\title{
Advanced Manufacturing Technology Projects Justification
}

\author{
Josef Hynek and Václav Janeček \\ University of Hradec Králové, Faculty of Informatics and Management \\ Czech Republic
}

\section{Introduction}

Manufacturing companies worldwide are pressurized to undergo a transformation processes in order to compete more effectively and under these circumstances advanced manufacturing technology (AMT) is considered to be a very important tool improving their ability to succeed with their products on extremely competitive international markets. It is widely believed that AMT has a great potential to provide the respective companies by a whole variety of tangible as well as intangible benefits and the reduction of production cost, increased volume of production, improved quality as well as better safety at work are usually amongst the most mentioned ones. On the other hand it is also generally understood that the adoption of AMT requires a high level of initial investment and also the level of risk associated with the implementation of the AMT project is higher especially when the particular company lacks relevant experience. Moreover the payback period of advanced manufacturing technology investment is as a rule longer than the payback period of rather traditional and usually less expensive technology. That is why the process of adoption and utilization of advanced manufacturing technology has been carefully studied and examined in last two decades and numerous studies were published in order to provide some guidelines for managers of manufacturing companies with the view of helping them to make good and well-founded decisions.

We also strongly believe that it is important to study the respective processes when the crucial decisions about AMT projects justification resulting into their practical implementation or on the contrary their rejection are made. The deep comprehension of the fundamentals of these processes allows us to derive the appropriate pieces of knowledge that could turn out to be helpful to technology specialists. We will present selected results of two extensive surveys targeted on adoption and utilization of advanced manufacturing technology that were carried out recently in the Czech Republic in this chapter. We will focus on the phase of advanced manufacturing technology project economic justification and findings ascertained in the Czech Republic will be compared with the outcomes of analogous surveys that were carried out earlier in the United Kingdom and the United States of America. We will demonstrate there are many problems of advanced manufacturing technology projects justification that we have in common in all the above 
mentioned countries and we believe that technology specialists as well as managers worldwide could learn from issues presented and discussed here.

Based on our results we suppose that technology specialists empowered in advance by broader insight of what kind of difficulties to anticipate they should be able to prepare their AMT projects accordingly and to improve their chance to get the management approval for the project financing and its implementation.

\section{Problem definition}

We have already pointed out that advanced manufacturing technology is rather expensive and the relevant project is associated with a higher degree of risk. Therefore the proper and sound justification of the investment decision is required. If the project is incorrectly undervalued and it does not get through the justification process, the company will miss the opportunity to derive potential benefits and its competitiveness might be jeopardized. On contrary, if the project is overvalued because of technology enthusiasm or because of the other reasons, it will be implemented and then it is likely that it will not meet the initial expectations. It will cause a disappointment and furthermore, it will complicate the justification process for further AMT projects that will be perceived through biased lens as the former experience was not a positive one. Whatever the motives are, we can see that the both problems, underestimation as well as overestimation of AMT projects, are terribly wrong and unfortunate. That is why the appropriate methods used for AMT projects justification and their proper utilization are extremely important.

It is widely accepted that there are three general groups of investment appraisal techniques economic approach, analytic approach and the strategic approach. The economic justification approach seems to be very natural and straightforward one and perhaps that is why it is so wide-spread in relevant companies worldwide. AMT investment has to be financially sound and viable because such a project competes for limited resources with many other projects. Therefore various financial and accounting justification techniques such as payback period (PP), return on investment (ROI), net present value (NPV), and internal rate of return (IRR) are frequently used by managers in order to assess the economic aspects of the project. However, many researchers argue that these methods support decisions that are sensible when viewed in isolation and they do not always indicate the best action when we take into account the whole organizational context (Chan et al., 2001). Furthermore, these methods could be misleading when employing too short payback periods or too high discount rates, neglecting various benefits of the new AMT system or being unable to quantify them properly in financial terms. To overcome the problems inherent in using purely economic appraisal techniques, analytic and strategic appraisal approaches have been promoted.

The analytic justification approaches are predominantly quantitative but more complex than the economic techniques. It is believed that especially when intangible benefits are taken into account, these techniques can be far more appropriate by being more realistic, offering better reflection of reality and taking more factors into consideration (Meredith \& Suresh, 1986). Various scoring and ranking models could be used including some traditional optimization techniques as well as risk analysis approaches. It is clear that the transformation process from the decision problem to the particular model involves a great deal of simplification and many important factors could be easily overlooked. Furthermore, 
models involving various weights of individual factors are rather vulnerable to bias brought along with subjective judgments.

The strategic justification approaches tend to be less technical that economic and analytic methods, but it should be stressed that they are quite often used in combination with them. The main advantage of the strategic approaches is their direct linkage to the goals of the company. Criteria such as meeting the business objectives, comparison with competitors, the retention or attainment of competitive advantage and industry leadership might be utilized as suitable factors for the relevant decision making processes where AMT projects are scrutinized. Of course, it would be unwise to assign too much importance to strategic justification methods and to overlook the economic and tactical impact of the project. That is why recent studies have promoted hybrid approaches based on suitable combination of economic, analytic and strategic appraisal techniques (see (Raafat, 2002)).

We will focus on the economic justification techniques in the rest of this chapter. These techniques seem to be widely used in manufacturing companies worldwide when the decision concerning AMT investments should be made. It is quite natural because the cost of such project is usually well known (although it could be very easily underestimated too) and it is necessary to cover the cost by relevant revenues and various benefits. We will show some typical problems related to the utilization of economic justification techniques and we would like to stress that some researchers have even claimed that these techniques are inappropriate for evaluating AMT projects (Bucher \& Lee, 2000).

\section{Literature review}

There are many interesting papers describing various issues of AMT projects justification from different points of view. Perhaps the easiest way to get quickly oriented in the field is to start with a comprehensive bibliography on justification of AMT (Raafat, 2002) that cites over two hundred articles from a variety of published sources. Chan et al. (2001) concisely reviewed various approaches used in the process of investment appraisal of AMT and concluded that improved approach that would integrate the currently used evaluation approaches was needed. Abdel-Kader \& Dugdale (1998) wrote an interesting paper reporting the results of a survey investigation into the investment decision making practices of large UK companies and their study focused especially on investments in AMT. On the other hand, Ariss, Raghunathan \& Kunnathar (2000) published their findings concerned factors affecting the adoption of AMT in small manufacturing firms in the United States. Hofmann \& Orr (2005) presented the results of their postal survey that was conducted amongst German manufactures and one part of their questionnaire was devoted to the assessment of AMT proposal too. Finally, we have decided to put forward the paper written by Small (2006) that summarizes the results of investigation on the justification of investments in AMT at US manufacturing plants.

We proudly acknowledge that the biggest motivation to start our own investigations in the field of AMT in the Czech Republic came from the work of Lefley \& Wharton (1993), Lefley (1994), and Lefley \& Sarkis (1997). These authors examined carefully the investment appraisal processes in the United Kingdom and the United States of America. They carried out extensive surveys both in the UK and the USA in order to learn more about current practices in respect of capital investment in AMT projects, to identify if there were perceived difficulties in appraising these projects and to elicit the opinions of senior executives on the 
various issues related to AMT projects evaluation. Among other things they found out that AMT projects were evaluated by the simplest financial criteria that seem to be unsuitable in this respect. Moreover, they realized that financial directors do have many difficulties when assessing various benefits of AMT projects, and finally, that investment into AMT could be easily influenced by business culture where managers are under pressure to produce shortterm results.

The first study in this field in the Czech Republic (Lefley et al., 2004) revealed that despite of many differences ascertained especially in the extent as well as the level of evaluated and implemented technology, where Czech manufacturing companies lagged behind their western competitors, there were many problems that were common for managers from all the three surveyed countries. These results fostered our interest to conduct the second survey in the Czech Republic in 2005 in order to identify the relevant changes in the results that were expected due to the quickly transforming Czech economy and its openness. And finally, we undertook the last survey in the Czech Republic in 2008 and we were interested in evaluation of AMT benefits this time. The results of this investigation are being carefully analyzed, processed statistically and we plan that we will be able to publish them later this year. However, the survey results described below have been derived from the first and the second survey only.

\section{Survey methodology}

To keep in line with the earlier UK and US surveys which were used as a basis for comparison we have decided to employ the same questionnaire as Lefley \& Wharton (1993) utilized earlier for their investigations. We translated their original English questionnaire into Czech language and verified its localization by means of a pilot survey.

The original questionnaire comprised of three sections. Questions in the first part were intended to establish the level of implementation of AMT that had been achieved to date. Three levels of AMT were identified which correspond to the levels of sophistication proposed by Dornan (1987) and Meredith \& Suresh (1986). Level 1 systems cover standalone projects e.g. robots, NC machines, CAD etc. Level 2 systems are linked systems e.g. linking together of a number of CNC machines, CAD/CAM etc., and Level 3 systems are fully integrated systems including computer integrated manufacturing (CIM) and flexible manufacturing systems (FMS).

In part number two of the survey the respondents were asked which techniques and criteria were used in capital project appraisal and what methods, if any, were used to measure and take into account project risk. Information was obtained about the measures used to assess the performance of senior executives as it appears that management in general is reluctant to make long-term risky investments (such as those in AMT) and prefers to invest in shortterm projects that show early profits and low risk (Lefley, 1994).

The third part of the survey was designed to explore opinions about the need for AMT investment, the efficacy of the investment criteria used and the extent to which other factors and considerations had a bearing on capital investment decisions.

We added one more additional section to the questionnaire that was used in the Czech Republic in 2005. It was devoted to the utilization of EVA (economic value added) indicator in our companies as there were some suggestions that there might be a relationship between utilization of this concept and investment behavior of manufacturing companies. 
To assure a straightforward comparison of collected data in different countries we carefully followed the methodology used by our predecessors. The survey was aimed at those companies who, it was believed, would have had some experience in the appraisal of AMT projects and that the person who was asked to complete the questionnaire should have had a significant contribution to make in final investment decision. A number of databases were reviewed (with the main stress on data acquired from EDB and Czech business register) to identify the largest manufacturing companies. As we wanted to restrict the survey to 'large' Czech manufacturing organizations, we finally chose sample size of 416 firms in 1999. Within our last survey we have decided to include also the middle sized Czech manufacturing firms and so we have increased the sample to 1030 in 2005.

Our first postal survey started at the end of 1998 and of the 416 questionnaires sent out 92 was returned giving a response rate of $22.12 \%$. A usable sample of 79 completed questionnaires with a response rate of $19.0 \%$ was considered to be reasonable under the existing circumstances.

The second postal survey has been conducted from January till April 2005 and 1030 questionnaires were sent out and 135 have returned, 3 of them were unusable. We can see that the rate of response is $12.8 \%$ only which is significantly lower rate that the one we achieved in 1999. The reason that we did not reach comparable numbers with our former survey could be explained by the fact that in our current survey the middle sized firms were addressed too.

This article deals with the selected results derived from the first three parts of our questionnaire only and due to limited space we cannot dwell on the other issues here. Readers who are interested in further details are advised to look at (Hynek \& Janeček, 2007) or (Hynek \& Janeček, 2008).

\section{Survey results and discussion}

The main part of this section will be devoted to economic justification of AMT projects, but we believe that the facts we will present here should be perceived in a broader context. That is why we will outline basic facts concerning the experience of Czech companies in the area of AMT projects evaluation as well as the levels of implemented technology that were achieved by surveyed companies. Furthermore, selected personal opinions of managers will be put forward in order to show some important problems and difficulties that could significantly influence the chance of AMT projects to pass successfully through the evaluation process.

\subsection{Appraisal experience and level of AMT}

First of all, from the point of view of further discussions concerning AMT projects justification it could be worthwhile to learn more about the experience of Czech manufacturing companies in the area of AMT projects evaluation. We can see from table 1 that $82.3 \%$ in year 1999 and $78.3 \%$ in year 2005 of Czech manufacturing companies claimed they had evaluated AMT projects. These numbers are significantly lower than results described by Lefley and Sarkis (1997) who reported that $99.3 \%$ of UK and 96.7 of US companies stated that they had evaluated AMT projects over the past ten years. It is clear that Czech managers are less experienced in this respect. Moreover, we have to take into account the time difference among the surveys. 
Furthermore, $84.8 \%$ of Czech manufacturing companies in year 1999 and $92.3 \%$ in year 2005 stated that they expect to consider such projects within the next ten years. Once again, comparing these findings with $97.1 \%$ of respondents in UK and $99.2 \%$ in US (Lefley \& Sarkis, 1997), there is a significant difference here despite the fact that the latter result ascertained in the Czech Republic might be considered as a positive signal evidencing the raising awareness of the importance of AMT projects amongst Czech managers.

\begin{tabular}{|l|c|c|}
\hline AMT projects evaluated & 1999 & 2005 \\
\hline Number of companies & 65 & 101 \\
\hline Percentage & $82.3 \%$ & $78.3 \%$ \\
\hline Total number of companies & 79 & 132 \\
\hline
\end{tabular}

Table 1. Companies that had evaluated AMT investment proposals

Secondly, we were interested in the level of manufacturing technology that was taken into consideration and consequently the level of technology that was actually implemented in the surveyed companies. There were some thoughts that massive foreign investment into transforming and quickly developing Czech economy during last two decades could accelerate the processes of adoption of advanced technology in manufacturing companies. The respective results are summarized in the table number 2 and 3 below.

\begin{tabular}{|l|c|c|}
\hline $\begin{array}{l}\text { \% number of companies that } \\
\text { evaluated AMT project at: }\end{array}$ & $\begin{array}{c}1999 \\
{[\%]}\end{array}$ & $\begin{array}{c}2005 \\
{[\%]}\end{array}$ \\
\hline Level 1 (stand alone projects) & 57.0 & 40.4 \\
\hline Level 2 (linked systems) & 35.4 & 41.3 \\
\hline Level 3 (fully integrated systems) & 15.2 & 18.3 \\
\hline
\end{tabular}

Table 2. Level of evaluation of AMT projects

\begin{tabular}{|l|c|c|}
\hline \% number of companies that & 1999 & 2005 \\
implemented AMT project at: & {$[\%]$} & {$[\%]$} \\
\hline Level 1 (stand alone projects) & 51.6 & 45.0 \\
\hline Level 2 (linked systems) & 33.9 & 36.9 \\
\hline Level 3 (fully integrated systems) & 14.5 & 18.0 \\
\hline
\end{tabular}

Table 3. Level of implementation of AMT projects

It is clear that many projects that were originally planned on a higher level were unable to reach the stage of practical implementation and only the restricted version of the project (on a less sophisticated level of technology) was carried out. There is an obvious positive tendency that we can see in the table number 2 as the percentage of Czech manufacturing companies that evaluated the higher level AMT project proposals have been increased in 2005. The same is true for the implementation stage but comparing these results internationally we have to admit significant differences in respect of stages reached by UK, US and Czech manufacturing companies in relation to the evaluation and implementation of AMT projects. For example, taking into account the results of British and US surveys (Lefley \& Sarkis, 1997) it is unmistakable that significantly greater number of UK (55.1\%) and US companies $(50.9 \%$ ) had evaluated the most sophisticated projects (on the third level) while the Czech companies have in majority only the first and the second level experience (we can see from table 2 that only $18.3 \%$ of companies reached the third level technology evaluation experience). 
Moreover, based on the results shown in table number 3 it is evident that Czech manufacturing companies are lagging behind their British and American competitors in the adoption of advanced manufacturing technology. The contrast is especially visible when focusing on the most advanced fully integrated systems (only $18.0 \%$ of Czech firms implemented them comparing to the $43.0 \%$ in the UK and $43.4 \%$ in the USA). Moreover, as we can see in table number 3 the situation in the Czech Republic has not changed very much between 1999 and 2005 and therefore the gap is still huge (Hynek \& Janeček, 2007). It is obvious that the high level of foreign direct investment in the Czech Republic did not fetch along anticipated acceleration of advanced technology adoption in manufacturing companies and the achieved levels of AMT implementations are lower than those previously observed in the UK and USA. Unfortunately, as we will discuss below, we have found that reasons for this unfavorable position of Czech manufacturing companies does not lie with lack of investment money only but it might be deeply rooted in management attitudes too.

\subsection{AMT projects justification}

Our findings that were described in the previous section clearly demonstrated that the level of AMT evaluation as well as its utilization in the Czech Republic is lower than the levels observed earlier in the UK and the USA. Furthermore, we have indicated that the process of AMT adoption might be influenced by management attitudes towards technology investment in general and, of course, the particular evaluation and justification approaches chosen by the relevant decision makers could be seen as a direct and straightforward way of influencing the outcome of the AMT projects evaluation processes. Some researchers and technology promoters expressed their concerns over conventional appraisal techniques such as payback, return on investment, or net present value, claiming that these techniques are inadequate and biased against technological investment in general (see, for example, Chan et al, 1999). Their criticism is based on assumption that while the cost of the proposed AMT project is in general easily quantifiable, there are many benefits that are very often difficult to estimate. Moreover, as AMT projects tend to be of long-term nature and sometimes even full deployment of particular AMT project requires substantial time period, the profits cannot be expected in short time and that is why the decisions on these projects require a long-term perspective. Subsequently, if the chosen appraisal method is well known for favoring short term profits, the relevant investment decision that is based on such method is easily predictable.

Table 4 shows financial criteria used to assess AMT projects by financial directors of Czech manufacturing companies. It is obvious that more than $60 \%$ of Czech managers employ the simple non-discounted cash flow payback period (non-DCF Payback) as the criterion to decide whether to finance such a project or not (see table 4 for more details) and more than $70 \%$ of them use discounted version of payback (DCF Payback). And it is exactly payback criterion that is often criticized and attacked for its inappropriateness regarding AMT projects. Naturally, this criterion prioritizes projects capable of early repayment of initial expenses while as a rule capital intensive AMT projects tend to be slow in generating positive net cash flows. Indeed, many argue that the utilization of the payback method virtually guarantees the rejection of projects such as AMT (Lefley et al, 2004). On the other hand it has to be stressed, that the problem is not caused by the criterion itself, but it arises when a short payback period is requested by the company management. As we can see in 
(DeRuntz and Turner, 2003), while the western companies generally accept a payback period of 1 to 5 years as a reasonable amount of time to recover the initial cost, the Japanese companies are much more flexible in this respect as they use the payback method more as a performance measure than as a rigid financial criterion that must be met.

\begin{tabular}{|l|c|c|}
\hline Financial appraisal criteria used & $\begin{array}{c}1999 \\
{[\%]}\end{array}$ & $\begin{array}{c}2005 \\
{[\%]}\end{array}$ \\
\hline IRR/yield & 31.1 & 35.5 \\
\hline NPV & 45.9 & 38.7 \\
\hline DCF Payback & 71.6 & 76.6 \\
\hline Other DCF & 5.4 & 10.5 \\
\hline Non-DCF Payback & 63.5 & 62.1 \\
\hline ARR & 35.1 & 23.4 \\
\hline Other non-DCF & 1.4 & 2.4 \\
\hline
\end{tabular}

Table 4. Financial appraisal criteria

It has been anticipated that many companies would use more than one criterion and that is why we have made inquiries regarding the number of financial appraisal criteria being used and their importance. The results are summarized in tables 5 and 6 . It should be noted that percentages given in table 6 below add up to more than $100 \%$ because some respondents gave equal first ranking to more than one technique.

\begin{tabular}{|c|c|c|}
\hline Number of methods used & $\begin{array}{c}1999 \\
{[\%]}\end{array}$ & $\begin{array}{c}2005 \\
{[\%]}\end{array}$ \\
\hline 1 & 23.0 & 22.6 \\
\hline 2 & 32.4 & 33.1 \\
\hline 3 & 20.3 & 25.0 \\
\hline 4 or more & 24.3 & 19.3 \\
\hline
\end{tabular}

Table 5. Number of different financial appraisal methods used

\begin{tabular}{|l|c|c|}
\hline Criteria ranked first or first equal & $\begin{array}{c}1999 \\
{[\%]}\end{array}$ & $\begin{array}{c}2005 \\
{[\%]}\end{array}$ \\
\hline IRR/yield & 5.4 & 9.7 \\
\hline NPV & 28.4 & 17.7 \\
\hline DCF Payback & 51.4 & 58.1 \\
\hline Other DCF & 1.8 & 4.0 \\
\hline Non-DCF Payback & 43.2 & 62.1 \\
\hline ARR & 13.5 & 8.9 \\
\hline Other non-DCF & 0.0 & 1.6 \\
\hline
\end{tabular}

Table 6. Percentage of companies ranking criteria first

It is definitely a positive ascertainment that more than $40 \%$ of financial directors use more than two financial criteria when assessing an AMT project proposal. On the other hand it is evident that every fifth company relies on single criterion only and here of course the important issue is which criterion is employed in these cases. We can see from table 6 that Czech managers without any doubt prefer both versions of payback criterion. Moreover, within our last survey the above mentioned and criticized simple non-discounted cash flow payback period (non-DCF PB) has been ranked as the most important one in the Czech Republic (62.1\% in 2005) while discounted version of this criterion came second (58.1\%). It 
should be emphasized that there is a huge gap afterwards as the third most important criterion (net present value) maintained its position from 1999 but it was ranked as the most important criterion by $17.7 \%$ of Czech managers only in 2005.

Comparing these results with earlier ascertainments of Lefley and Sarkis (1997) we could find out that non-discounted cash flow payback period (non-DCF PB) was ranked as the number one criterion in the United Kingdom (38.5\%). American managers inclined to use more sophisticated methods that make allowance for the time value of money and that is why DCF Payback (ranked first by $33.3 \%$ of managers) was closely followed by internal rate of return (IRR) that was preferred by $28.2 \%$ of US managers. From this point of view it is quite interesting that IRR is rather popular amongst British managers too (28.0\%), while only $5.4 \%$ of Czech managers in 1999 and $9.7 \%$ in 2005 marked it as the most important criterion.

It should be noted that the higher number of methods and techniques used within AMT projects evaluation process should be facilitated by various pieces of software. Therefore, companies were asked if spreadsheet packages, dedicated software or other computer aids were used in the process of evaluating advanced manufacturing technology investment proposals and the results are shown in table 7. We can see that a very high proportion of Czech companies use spreadsheet software (75.7\% in 1999 and even $89.4 \%$ in 2005). Approximately one out of six managers employs some dedicated computer software, while other computer aids were reported to be used semi-occasionally.

Table 7. Use of computer aids

\begin{tabular}{|l|c|c|}
\hline Computer aids & $\begin{array}{c}1999 \\
{[\%]}\end{array}$ & $\begin{array}{c}2005 \\
{[\%]}\end{array}$ \\
\hline Spreadsheets & 75.7 & 89.4 \\
\hline Dedicated software & 16.2 & 18.3 \\
\hline Other computer aids & 4.1 & 4.8 \\
\hline
\end{tabular}

Of course, it was anticipated that conventional criteria are widely used and therefore the respondents were asked to indicate, based on their own experience and judgment, whether or not they agreed with the statement that, "conventional appraisal methods such as Payback, NPV and IRR favored short term projects". According to (Lefley \& Sarkis, 1997) more than $70 \%$ of companies in the UK and USA agreed with the statement, while significantly fewer in the Czech Republic (55.6 \% in 1999 and $53.2 \%$ in 2005) were of the same opinion. The relatively low proportion of Czech managers who thought conventional techniques favor short term investments seems to support the above mentioned views that conventional financial appraisal methods do not automatically favor short-term projects and that these criteria could be used for AMT project proposal evaluation too. Of course, these techniques should be used wisely because when short payback periods or unjustifiably high discount rates are used then a short-term bias can easily occur.

In this respect it could be interesting to find out if there is a tendency to set up some tight hurdle rates for AMT projects justification in companies. The respondents were asked to express their level of agreement with the relevant statement and their responses are summarized in table 8 .

We can see that nearly every second manager agreed with the statement and admitted that there is a tendency to set up very tight hurdle rates which could indicate rather disadvantageous starting position for AMT projects. High hurdle rates in combination with 
the above mentioned traditional appraisal methods could easily result in the AMT project rejection. On the other hand we have to say that in many cases the high hurdle rates are used by managers in order to make appropriate adjustment for a higher degree of risk and uncertainty that relates to AMT projects and it is rather typical approach taken by many companies worldwide when evaluating more risky investment project. Hence such behavior should not be automatically perceived as deliberate intention to discriminate against AMT projects especially when the particular company lacks experience with the project proposal that is under consideration.

\begin{tabular}{|l|c|c|}
\hline $\begin{array}{l}\text { There is a tendency to set too high } \\
\text { a hurdle rate for AMT projects. }\end{array}$ & $\begin{array}{r}1999 \\
{[\%]}\end{array}$ & $\begin{array}{r}2005 \\
{[\%]}\end{array}$ \\
\hline Agree & 48.0 & 48.8 \\
\hline Disagree & 52.0 & 51.2 \\
\hline
\end{tabular}

Table 8. There is a tendency to set too high hurdle rates for AMT projects

Some researchers as well as practitioners advocate for exploitation of non-financial criteria and rather strategically oriented criteria believing that there is too much importance attached to conventional techniques. That is why the respondents were asked to express, based on their own experience and judgment, whether or not they agreed with the statement that, "too much importance is attached to conventional techniques". Their responses are presented in table 9 .

\begin{tabular}{|l|c|c|}
\hline $\begin{array}{l}\text { Too much importance is attached } \\
\text { to conventional techniques }\end{array}$ & $\begin{array}{c}1999 \\
{[\%]}\end{array}$ & $\begin{array}{c}2005 \\
{[\%]}\end{array}$ \\
\hline Agree & 51.4 & 44.4 \\
\hline Disagree & 48.6 & 55.6 \\
\hline
\end{tabular}

Table 9. Too much importance is attached to conventional techniques

It is clear that Czech managers do not feel like having a serious problem with conventional appraisal techniques utilization and their views are perfectly conformable with the opinions of British and US managers where also slightly less than five out of ten managers agreed with the above presented statement that too much importance is attached to conventional appraisal techniques.

It was also noted (Hynek \& Janeček, 2007) that a high proportion of companies in all three countries (83.4\% on an average) referred back for re-appraisal those proposals that had failed the initial financial appraisal (the results concerning the situation in the Czech Republic are displayed at table 10). Of course, the introduction of a referral process into the investment justification procedure creates further opportunity for managers to examine the whole proposal carefully once more, to take into account strategic considerations, re-assess and quantify potential benefits or even adjust financial criteria that has to be fulfilled (for example, by reduction of required payback period, or by lowering the pertinent discount rates). On the other hand, it is the very same moment when exactly opposite measures and actions could be taken and there is a large space in which the accept/reject decision could be manipulated. It could be anticipated that in these cases the formal appraisal procedure transforms itself into a ritual where the final decision is based on other influences, which might be of a political, rather than an economic nature. In this context we should put and 
understand the interesting fact that more than eight out of ten respondents confirmed the referral procedure.

\begin{tabular}{|l|r|r|}
\hline Project proposals re-evaluated & $\begin{array}{r}1999 \\
{[\%]}\end{array}$ & $\begin{array}{r}2005 \\
{[\%]}\end{array}$ \\
\hline Agree & 89.2 & 81.5 \\
\hline Disagree & 10.8 & 18.5 \\
\hline
\end{tabular}

Table 10. Percentage of proposals re-appraised

Having admitted that there might be some political influence in the referral procedure and in the projects evaluation process in general it is natural to ask to which extent do senior executives use their dominant role based on their formal as well as informal authority in order to affect the relevant decisions related to AMT investment in both directions. That is the reason why the respondents were asked to express their level of agreement with the statement that more importance is attached to the experienced judgment of senior management than to financial indicators. The results are shown in table 11 and we can see that slightly over fifty percent of Czech respondents agreed with the statement in 1999 $(51.9 \%)$ and their number declined further in 2005 (45.7\%). Nevertheless, it should be stressed that the number of managers who agreed with the statement is relatively high overall and it is clear the concerns expressed by some researchers as well as practitioners seems to be legitimate.

\begin{tabular}{|l|c|c|}
\hline More importance is attached to & & \\
the experienced judgment of & $\begin{array}{c}1999 \\
\text { senior management than to } \\
\text { financial indicators }\end{array}$ & $\begin{array}{c}2005 \\
{[\%]}\end{array}$ \\
\hline Agree & 51.9 & 45.7 \\
\hline Disagree & 48.1 & 54.3 \\
\hline
\end{tabular}

Table 11. More importance is attached to the experienced judgment of senior management than to financial indicators

To conclude this section we would like to stress that despite the mentioned criticism the traditional financial appraisal techniques play important role in the process of AMT projects evaluation and justification. We have shown that managers prefer the simplest techniques like payback period that are very easy to understood and interpret, but we have also mentioned that there is a danger of bias towards projects delivering short-term profits when these techniques are used mechanically, shortsightedly, and without broader impact considerations. Furthermore, the risk that AMT projects would be disadvantaged by utilization of these simple techniques could be moderated by utilization of several methods and we have shown that more than eight out of ten projects are re-evaluated if they failed to pass through the initial financial evaluation process.

\subsection{Personal opinions of managers}

We have already mentioned that the process of AMT justification might be seriously influenced by management attitudes towards technology investment in general. AMT is often considered as one of critical factors that plays important role in the process of acquiring competitive advantage. It seems to be a widely accepted opinion but do managers 
really think so? We wanted to verify this ascertainment and the respondents were asked to indicate based on their own experience and judgment, whether or not they agreed with the statement that non-investment in AMT was a high risk strategy. Responses to this statement were summarized in table number 12 and we can immediately see there that surprisingly large proportion of executives in the Czech Republic (33.3\% in 1999 and 30.7\% in 2005) disagreed that non-investment in AMT is a high-risk strategy.

\begin{tabular}{|l|c|c|}
\hline Non-investment in AMT & 1999 & 2005 \\
is a high-risk strategy & {$[\%]$} & {$[\%]$} \\
\hline Agree & 66.7 & 69.3 \\
\hline Disagree & 33.3 & 30.7 \\
\hline
\end{tabular}

Table 12. Non-investment in AMT is a high-risk strategy

Comparing these findings with the results of Lefley and Sarkis (1997) who reported more than the decade ago than $74.8 \%$ in the UK and $81.9 \%$ in the US agreed with the statement that non-investment in AMT is a high-risk strategy, it is clear that significantly higher proportion of Czech managers do not consider AMT as strategically important investment. It is a rather surprising ascertainment taking into account that Czech manufacturing companies after transformation of our economy had to find new market opportunities for their products. Many of them oriented themselves mainly on strongly competitive markets in Western Europe, many others were sold to foreign investors and it was anticipated that new owners would bring new technologies too. It is difficult to generalize, but as we concluded in (Hynek \& Janeček, 2006a) it is likely that many companies have apparently decided to rely on skilful and relatively cheap labor force and that is why the relevant companies seems to be somewhat slow in AMT adoption. Moreover, we are afraid that in today's mutually interlinked and quickly changing global world the exploitation of such strategy sounds like a rather shortsighted decision.

Obviously it is not easy to change management attitudes towards AMT investment and perception of its importance from day to day. Fortunately enough, there are some other issues we should pay our attention too and we think that there might be some space where improvement of the current state of art is more feasible. Moreover, we will show that while there are significant differences in perception of the strategic importance of AMT investment in general between managers working under conditions of transforming Central European economy and managers representing two of the most developed countries in the world, there are some problems they have in common too. For example, we have learned that many AMT projects are likely to be rejected just because the lack of understanding of what the contribution of new technology really is.

We could see in table number 13 that more than $60 \%$ of Czech executives agree with the statement that it is difficult to assess all potential benefits of AMT investments $(67.1 \%$ in 1999 and $60.3 \%$ in 2005). The level of agreement with the relevant statement was even higher in the UK $(81.6 \%)$ while $63.9 \%$ of American managers shared the view (Lefley \& Sarkis, 1997).

Thinking about reasons that we can see three possible explanations of this unfavorable situation. First of all, there are some benefits where managers seems to be unable to foresee and to assess their impact and magnitude there because of lack of experience, lack of relevant input data etc. Secondly, the company is not sure whether some particular benefit will be realized at all and thus the benefit falls into this category and stays there without any 
attempt to quantify it. And thirdly, it is often believed that brand new technology will bring along some new benefits and completely unexpected benefits that are impossible to predict before the technology reach the stage of regular utilization. While the first problem seems to be based on lack of experience and administrative-technical reasons, the other two explanations seems to be much more of a speculative nature.

\begin{tabular}{|l|c|c|}
\hline $\begin{array}{l}\text { AMT investments are difficult to } \\
\text { assess because they have } \\
\text { non-quantifiable benefits }\end{array}$ & $\begin{array}{c}1999 \\
{[\%]}\end{array}$ & $\begin{array}{c}2005 \\
{[\%]}\end{array}$ \\
\hline Agree & 67.1 & 60.3 \\
\hline Disagree & 32.9 & 39.7 \\
\hline
\end{tabular}

Table 13. AMT investments are difficult to assess

However, whatever reason applies it helps to create the feeling that there are some non-quantifiable benefits that were not taken into account. And we will demonstrate that there is a problem related to proper assessment of non-quantifiable benefits and their expression in financial terms which means that these benefits will not be taken into relevant economic calculations.

We can see in table 14 that large majority of Czech managers $(90.1 \%$ in 1999 and $81.7 \%$ in 2005) agreed with the statement that not all potential benefits of AMT are taken into account because they are difficult to quantify in financial terms. It should be noted that these numbers are in compliance with the earlier findings of (Lefley \& Sarkis, 1997) who reported that $80.9 \%$ of British managers agreed with the statetems and $81.2 \%$ of American managers did so. It is important to repeat here that the respondents of our surveys were financial directors and decision makers of surveyed manufacturing companies. Recalling back this fact we can see that the situation is very serious and some measures should be taken in order to make sure that AMT project proposals have a fair chance to get through the justification process and to get the pertinent investment approval.

\begin{tabular}{|l|c|c|}
\hline $\begin{array}{l}\text { Not all potential benefits of AMT } \\
\text { are taken into account because } \\
\text { they are difficult } \\
\text { to quantify in financial terms }\end{array}$ & $\begin{array}{c}1999 \\
{[\%]}\end{array}$ & $\begin{array}{c}2005 \\
{[\%]}\end{array}$ \\
\hline Agree & 90.1 & 81.7 \\
\hline Disagree & 9.9 & 18.3 \\
\hline
\end{tabular}

Table 14. Not all benefits are taken into account

According to Primrose (1991) people advocating investment in AMT have made considerable efforts to identify the company-wide benefits which it can produce. The problem is that they describe these benefits always in general terms, such as the following: increased flexibility of production, better-quality products, improved documentation, ability to respond to market needs, need to keep up with competition, improved company image, better management control, obtaining experience of new technology, etc. Managers usually start with the belief that a particular aspect of AMT could be used in their department and they would select an application which was aimed at improving operating efficiency. Having defined the required specification, they try to justify the expenditure afterwards. And now it is necessary to identify the benefits. The nature of intangible benefits is such that they do not have to appear in the department where the investment is made, but occur 
elsewhere in the company. In addition, the relationship between cause and effect is indirect, so that their magnitude has to be estimated rather than directly calculated. In fact there are two distinct problems and these must be dealt with separately. First of all the form in which the benefit is quantified, and secondly estimating the magnitude of the benefit (see (Primrose, 1991) for more details).

\section{Conclusions}

The presented selected results of two AMT surveys focused on the specific issues of advanced manufacturing technology justification that were carried out in the Czech Republic demonstrate that the economic justification of the relevant projects is definitely not an easy process. Moreover, there are many problems that seem to be common for managers in Central Europe who has to face the conditions of transforming economy and managers from technologically most developed economies in the world.

First of all, our results clearly demonstrate that Czech manufacturing companies are lagging behind their British and American competitors in the adoption of AMT and the optimistic prognoses that the high level of foreign direct investment will bring along acceleration of AMT adoption as well as the latest technology has not been proved yet.

We have also shown some pieces of evidence that AMT projects might be very easily knowingly as well as unknowingly disadvantaged because of a whole spectrum of reasons. Based on our results it is clear that managers exploit rather unsuitable financial criteria, too much importance is given to the simplest methods that clearly prioritize short-term outcomes and thus short-term projects. British and American managers seem to be more aware of this fact and perhaps it is the reason why they tend to utilize more sophisticated criteria and greater number of criteria in general than managers in the Czech Republic do. However, we have stressed that the problems could be avoided if the criteria are used wisely and we have mentioned as an example the difference between payback period utilization in western companies on one side, and Japanese companies on the other one.

We have seen that more than eight of out ten AMT projects are re-evaluated if they failed the initial financial appraisal. As the result of this phenomenon many projects are carried out only partially. It could be the restricted version of the original project that lacks the originally intended level of integration, or it could be done at the expense of the originally planned level of technology used. In both cases there is a danger that restricted version of the originally planned AMT project will be unable to deliver originally planned benefits and the project will not live up the expectations. Furthermore, we have pointed out that introduction of the referral process establishes ground for various influences that might be of a political rather than economic nature.

Finally, we have examined management attitudes towards AMT projects. We have realized that comparing our results with the outcomes of earlier survey conducted in the UK and USA, significantly higher proportion of Czech managers do not consider AMT as strategically important investment. On the other hand, there are some serious issues that significantly influence the process of AMT adoption and these issues are common for the managers from all three surveyed countries. First of all, two thirds of managers agreed with the statement that AMT investments are difficult to assess because they have nonquantifiable benefits. Secondly, over eighty percent of respondents supported the view that not all potential benefits of AMT are taken into account because they are difficult to quantify 
in financial terms. Putting these ascertainments in other words we can see that there is a clear lack of understanding of what the contribution of the proposed AMT project really is. Moreover, managers are fully aware of the fact that some benefits are not taken into their calculations because they are unable to estimate them and express them in financial terms. We have already expressed (Hynek \& Janeček, 2006b) our view that there is an important space and great opportunity right here that should be taken by technology specialists. They should be able to identify, describe and explain the complex benefits of a particular AMT project and hereby prepare better background material for financial executives. Their involvement in this phase could assure that various tangible as well as intangible benefits will be taken into consideration, properly assessed and consequently expressed in financial terms. Of course, this task could be fulfilled only by technology experts who are able to see the particular technology not simply from technological point of view. Their knowledge and broader understanding of technology benefits for the company as a whole could considerably improve the chances of AMT projects to get the management approval.

Of course, it should be also accentuated that economic approach to AMT projects justification is widely used but it is not the single approach and we recommend employing strategic and analytical approaches too. These approaches do have their own drawbacks too and therefore wise combination of different approaches should be encouraged in order to make sure that AMT project proposals are assessed properly. This is the only way providing enough opportunities to avoid later disappointment.

\section{Acknowledgement}

This research has been supported by the Grant Agency of the Czech Republic project No. 402/07/1495.

\section{References}

Abdel-Kader, M. G. \& Dugdale, D. (1998). Investment in Advanced manufacturing technology: a study of practice in large U.K. companies. Management Accounting Research, No. 9, pp. 261-284, ISSN 1044-5005.

Ariss, S. S.; Raghunathan, T. S. \& Kunnathar, A. (2000). Factors Affecting the Adoption of Advanced Manufacturing Technology in Small Firms. SAM Advanced Management Journal, Vol. 65, No. 2, Spring 2000, pp. 14-29, ISSN 0749-7075.

Bucher, P.G. \& Lee, G.L. (2000). Competitiveness Strategies and AMT Investment Decisions. Integrated Manufacturing Systems, No. 11/5, pp. 340-347, ISSN 0957-6061.

Chan, F.T.S.; Chan, M.H.; Lau, H. \& Ip, R.W.L. (2001). Investment Appraisal Techniques for Advanced Manufacturing Technology (AMT): A Literature Review. Integrated Manufacturing Systems, No. 12/1, pp. 35-47, ISSN 0957-6061.

DeRuntz, B. D. \& Turner, R. M. (2003). Organizational Considerations for Advanced Manufacturing Technology. International Journal of Production Economics, Vol. 2002, No. 79, pp. 197-208, ISSN 0925-5273.

Dornan, S. B. (1987). Cells and Systems: Justifying the Investment. Production, February 1987, pp. 30-35.

Hofmann, C. \& Orr, S. (2005). Advanced Manufacturing Technology Adoption - the German Experience. Technovation, Vol. 25, No. 7, pp. 711-724, ISSN 0166-4972. 
Hynek, J. \& Janeček, V. (2005). Adoption of Advanced Manufacturing Technology - New Trends in the Czech Republic. In: Proceedings of the IEEE 9th International Conference on Intelligent Engineering Systems. IEEE, Piscataway, NJ, 2005, pp. 75-78, ISBN 07803-9474-7.

Hynek, J. \& Janeček, V. (2006a). Information Gap between Technology Specialists and Decision Makers. In: Proceedings of IEEE 3rd International Conference on Mechatronics, IEEE, Piscataway, NJ, pp. 61-64, ISBN 1-4244-9712-6.

Hynek, J. \& Janeček, V (2006b). Problems of Advanced Manufacturing Technology Projects Approval. In: Proceedings of the 5th WSEAS Int. Conf. on System Science and Simulation in Engineering (ICOSSE'06), Tenerife, Canary Islands, Spain, WSEAS Press, pp. 412-416, ISBN 960-8457-57-2, ISSN 1790-5117.

Hynek, J. \& Janeček, V. (2007). Advanced Manufacturing Technology Projects Justification. In: Proceedings of the 4th IEEE International Conference on Mechatronics, University of Kumamoto, Japan, 2007, pp. 277-282, ISBN 1-4244-1184-X.

Hynek, J. \& Janeček, V. (2008). Economic Justification of Advanced Manufacturing Technology, In: Proceedings of the 2nd WSEAS Int. Conf. on Management, Marketing and Finances (MMF'08), Harvard University, Cambridge, Massachusetts, WSEAS Press, 2008, pp. 103-108, ISSN 1790-5117.

Lefley, F. \& Sarkis, V. (1997). Short-termism and the appraisal of AMT capital projects in the US and UK. International Journal of Production Research, Vol. 35, No. 2, pp. 341-368, ISSN 0020-7543.

Lefley, F. \& Wharton, F. (1993). Advanced Manufacturing Technology Appraisal: A Survey of U.K. Manufacturing Companies. Proceedings of the 4th Int. Production Management Conference: Management and New Production Systems, London Business School, 1993, pp. 369-381.

Lefley, F. (1994). Capital investment appraisal of advanced manufacturing technology. International Journal of Production Research, Vol. 32, No. 12, pp. 2751-2776, ISSN 00207543.

Lefley, F.; Wharton, F.; Hájek, L.; Hynek, J. \& Janeček, V. (2004). Manufacturing investments in the Czech Republic: An international comparison. International journal of Production Economics. Vol. 88, No. 1, pp. 1-14, ISSN 0925-5273.

Meredith, J. R. \& Suresh, N. (1986). Justification techniques for advanced manufacturing technologies. International Journal of Production Research, Vol. 4, No. 5, pp. 1043-1058, ISSN 0020-7543.

Primrose, P. L. (1991). Investment in Manufacturing Technology. Chapman\&Hall, London 1991, ISBN 0412409208.

Raafat, F. (2002). A comprehensive bibliography on justification of advanced manufacturing systems. International Journal of Production Economics, Vol. 2002, No. 79, pp. 197-208, ISSN 0925-5273.

Small, M. H. (2006). Justifying Investment in Advanced Manufacturing Technology: a Portfolio Analysis. Industrial Management \& Data Systems, Vol. 106, No. 4, pp. 485508, ISSN 0263-5577. 


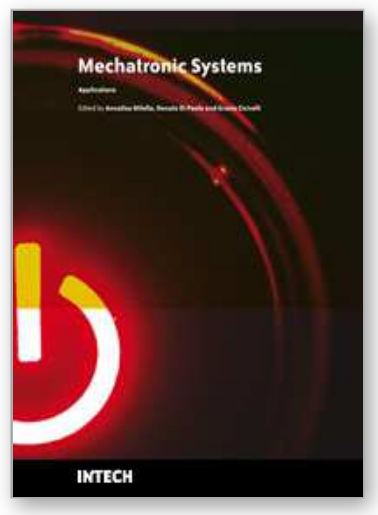

\author{
Mechatronic Systems Applications \\ Edited by Annalisa Milella Donato Di Paola and Grazia Cicirelli
}

ISBN 978-953-307-040-7

Hard cover, 352 pages

Publisher InTech

Published online 01, March, 2010

Published in print edition March, 2010

Mechatronics, the synergistic blend of mechanics, electronics, and computer science, has evolved over the past twenty five years, leading to a novel stage of engineering design. By integrating the best design practices with the most advanced technologies, mechatronics aims at realizing high-quality products, guaranteeing at the same time a substantial reduction of time and costs of manufacturing. Mechatronic systems are manifold and range from machine components, motion generators, and power producing machines to more complex devices, such as robotic systems and transportation vehicles. With its twenty chapters, which collect contributions from many researchers worldwide, this book provides an excellent survey of recent work in the field of mechatronics with applications in various fields, like robotics, medical and assistive technology, humanmachine interaction, unmanned vehicles, manufacturing, and education. We would like to thank all the authors who have invested a great deal of time to write such interesting chapters, which we are sure will be valuable to the readers. Chapters 1 to 6 deal with applications of mechatronics for the development of robotic systems. Medical and assistive technologies and human-machine interaction systems are the topic of chapters 7 to 13.Chapters 14 and 15 concern mechatronic systems for autonomous vehicles. Chapters 16-19 deal with mechatronics in manufacturing contexts. Chapter 20 concludes the book, describing a method for the installation of mechatronics education in schools.

\title{
How to reference
}

In order to correctly reference this scholarly work, feel free to copy and paste the following:

Josef Hynek and Vaclav Janecek (2010). Advanced Manufacturing Technology Projects Justification, Mechatronic Systems Applications, Annalisa Milella Donato Di Paola and Grazia Cicirelli (Ed.), ISBN: 978-953307-040-7, InTech, Available from: http://www.intechopen.com/books/mechatronic-systemsapplications/advanced-manufacturing-technology-projects-justification

\section{INTECH}

open science | open minds

\section{InTech Europe}

University Campus STeP Ri

Slavka Krautzeka 83/A

51000 Rijeka, Croatia

Phone: +385 (51) 770447

Fax: +385 (51) 686166

\section{InTech China}

Unit 405, Office Block, Hotel Equatorial Shanghai

No.65, Yan An Road (West), Shanghai, 200040, China 中国上海市延安西路65号上海国际贵都大饭店办公楼 405 单元

Phone: +86-21-62489820

Fax: +86-21-62489821 
www.intechopen.com 
(C) 2010 The Author(s). Licensee IntechOpen. This chapter is distributed under the terms of the Creative Commons Attribution-NonCommercialShareAlike-3.0 License, which permits use, distribution and reproduction for non-commercial purposes, provided the original is properly cited and derivative works building on this content are distributed under the same license. 